\title{
III THE EXCHANGE RATE REGIME AND PAYMENTS ADJUSTMENT
}

The Bretton Woods objective of stable but adjustable exchange rates sought to provide for adjustments in exchange rates to accommodate countries' domestic needs while avoiding unnecessary fluctuations produced by either aggressive national policy actions or spontaneous excesses of the market. This objective was and remains sound. The still unresolved problem is how to implement it. In this aspect, for the reasons explained below, the particular changes in the system on which official negotiations have focused are of doubtful adequacy to fulfil their intended task. The view taken in this report is that the objective of controlled flexibility of exchange rates is the proper one; but that different and in some respects more extensive innovations than those that have hitherto received serious official consideration are needed to achieve it.

The objective of controlled flexibility has f requently been assailed from both sides. On the one side, the appropriateness and even the propriety of adjusting exchange rates was widely questioned in official circles in the critical years $1960-66$. In this period the exchange adjustment mechanism of Bretton Woods became almost entirely passive, at least for the large economies. On the other side, in academic and other private circles, still stronger doubts have frequently been expressed about the wisdom of attempting to exert any official restraints on the free fluctuation of exchange rates in response to market forces.

Both these extreme positions have now been put to some test. The attempt to maintain exchange rates rigid in the face of major changes in the conditions of competitiveness among countries was eventually seen to involve excessive costs, in the first instance for the economy with the misaligned currency, and subsequently also for the international community in the shape of payments restrictions and distortions in domestic purchasing power. But the adjustment of exchange rates under the Bretton Woods mechanism, by a substantial step adjustment in parities, in turn set off increasing speculation on further such changes. This exposed the defect in the active use of the Bretton Woods exchange mechanism, its stimulation of dis ruptive speculation.

The Smithsonian Agreement of December 1971 included, as a compromise and interim expedient, a widening of the permitted margins for exchange rates to fluctuate around parity from one per cent to $2 \frac{1}{4}$ per cent on either side of parity between individual currencies and their intervention currency such as the U.S. dollar. This did not provide sufficient protection on its own against a renewal of overwhelming speculation. The Smithsonian parity system cracked in June 1972 with the floating of the pound sterling, and finally crumbled with the floating of all major currencies in February-March 1973. An attempt has continued to be made to maintain a stable band of rates between the currencies of members of the European Economic 
Community, but the significance of this has been limited by absence of the two currencies in potential disequilibrium - the pound sterling and the Italian lira - and by the recurring revaluations of parities within the EEC band (or "snake").

For an initial period in the second quarter of 1973 , the regime of virtually universal floating rates seemed to be functioning smoothly and satisfactorily. It was at this time that it was increasingly asked whether an organized international monetary system was needed at all. The market honeymoon was a brief one. In midsummer, sharp and sustained movements in major currencies carried exchange rates to levels that appeared unjustified on any analysis of the underlying competitive positions. This was a situation in which the mechanism of floating rates should have generated its own corrective, and for a time, exchange authorities made efforts to limit their intervention, in order to attract stabilizing speculation from market sources. Such stabilizing speculation did not emerge. The foreign exchange market witnessed the phenomenon observable in the experience of many developing countries in commodity markets: movements in market prices are far larger than analysis would suggest to be necessary, before inducing a reversal of a trend that is firmly underway.

In the foreign exchanges, as in commodity markets, excessive movements in prices can set up their own cycle of instability. For the industrial countries, excessive depreciations and appreciations can have perverse effects on the trade balance, exacerbating inflationary problems in the over-depreciating countries, and shielding the overappreciating countries from the domestic effects of rising commodity prices. For the developing countries, the wide and excessive divergence in rates for the currencies of major centres has brought haphazard shifts in import and export prices, as well as administrative problems of exchange support. There has therefore been a general welcome for the resumption by the major countries of official intervention to check excessive movements in market rates, with the help of an expanded network of swap credits. But the stabilizing influence of this readiness to intervene is limited in a number of ways as long as it remains entirely ad hoc in character, providing no frame for market expectations.

Probably the first need for a reformed international monetary system, which could be dealt with ahead of other aspects requiring more extensive preparation, is to establish a convincing operational framework for exchange rates to be in fact, and not only in name, stable but adjustable. The key ingredient for this difficult task is to provide for the possibility of continuous adjustment by small amounts in exchange parities, or in the range of potential rate fluctuation, while limiting the scope for market movements at any moment of time within the specified band around the parity, or its equivalent under managed floating. An approach of this kind foregoes "stability in the small" in 
the interests of better safeguarding "stability in the large". In fact little is sacrificed, because the significance of stability in the small in the shape of set parities is lost when changes in parities either take place frequently in sizeable steps, or if parities are frequently abandoned in favour of floating rates. And when parities of other currencies are changed, as noted above, a stable parity may no longer involve a stable effective exchange rate. An attempt to maintain set parities may therefore involve the sacrifice of the substance of exchange stability for its form.

The strongly expressed preference of developing countries for stability of exchange rates should be attainable to the extent of achieving reasonable stability over time, i.e. avoidance of extreme fluctuations. Institutional stability - fixity of parities in the short term - is likely to be a hindrance rather than a help in attainment of the substantive objective.

On this key point there appears to be a danger that official negotiations may be becoming engrooved on the wrong line. The broad pattern of reformed arrangements on which attention is focusing contains the following main elements: (i) parities would be generally reestablished, probably set in terms of the SDR, and perhaps maintained by multi-currency intervention; (ii) margins around these parities would be wider than the one per cent permitted in the Articles and perhaps wider also than the $2 \frac{1}{4}$ per cent agreed at the Smithsonian, which was however expressed against the intervention currency (allowing double the margin between third currencies); (iii) pressure on countries to adjust their parities would be exerted on an at least partly formalized basis, through the use of statistical indicators, or more judgmental assessments, to trigger active consideration of a parity change; (iv) these pressures would be applied in a progressive manner and would be backed by possible sanctions against the offending country, including new sanctions against surplus countries; such sanctions would be applied on aspects such as interest rates on reserve holdings, convertibility of foreign exchange balances, and perhaps also allocation of SDRs; (v) where establishment of a new parity or maintenance of the existing parity involved excessive risks, particularly of market speculation, provision would exist for resort to floating rates as a transitional or exceptional measu re.

While a regime of this kind attempts to deal with the problem of undue rigidity and tardy adjustment of parities, it offers little protection against the other endemic problem of a system of parity adjustment by substantial steps - the problem of anticipatory speculation. Indeed, unless parallel innovations are introduced in the form of parity change, the pressure for adjustment introduced by use of statistical indicators or formal international assessments is itself likely to intensify the speculation problem. The exchange rate regime could then become one dominated by its exceptions, with prolonged resort to floating rates. 
Unless agreement was also reached on rules or guidelines for management of rates of floating currencies, a regime of this kind would paradoxically contain no criteria for limiting fluctuations in those circumstances in which limitation was most necessary. It is encouraging that formulation of rules or guidelines for floating is now being given increased attention in the reform discussions.

Rather than a new exchange rate regime that risks gravitating between short-term fixity and unbounded flexibility, the objective should be to establish a system of continuous but limited flexibility. A variety of technical arrangements can be envisaged for such a system. Three alternative bases for such mechanisms - which certainly do not exhaust the list of possibilities - are as follows:

\section{Alternative (1) Managed Floating Subject to International Regulation}

Central parities would not be restored; exchange rates would be allowed to fluctuate subject to acceptance by Fund member countries of responsibility for checking excessive fluctuations in their currencies; the overall thrust of such intervention, as distinct from the daily operations, being coordinated in an international forum. A major criterion for coordination of exchange intervention would be the formulation of international guidelines for a permissible range in movement of member countries' basic payments balances (which in this regime would have distinct advantages over reserves as a target indicator). Thus statistical indicators and analytical assessments could play a comparable role to that envisaged under the new parity regime, with the benefit of more effective defence against anticipatory speculation.

\section{Alternative (2) Moving Parity Zones}

Central parities would be re-established, but countries would be free to change these parities at their discretion within an internationally agreed zone, of say ten per cant width. The permissible zone for each country concerned would be renegotiated in an international forum at periodic intervals. This system would require a relatively wide band for fluctuation of market rates around parity (distinct from the permissible zone for the setting of the parity), and the smooth working of the system would require frequent movements in parity well before the market rate had approached the limit of the band.

Alternative (3) Discretionary and Regular Parity Changes, Wide Margins The least formalized parity system consistent with reasonable safeguards against disruptive speculation would contain elements such as 
the following. Margins around parities would be wider than contemplated hitherto - e.g. the equivalent of five per cent in terms of the intervention currency, giving a band width of ten per cent, and more in the event of multiple currency intervention applying to all currencies (i.e. if countries maintained their rates by intervening in the currencies of all their partner.countries, rather than against a single third currency such as the U.S. dollar). No formal arrangements for parity changes would be laid down, but in order to avoid the build-up of anticipations of substantial step changes, the general practice would be adopted of announcing parities at regular intervals, e.g. weekly. An announcement could take the form of no change, but the system would require a routine of frequent changes - typically by small fractions of one per cent - in order to remove the rationale for speculative expectations that the initiation of a change was a sign of a forthcoming one way movemeit. The aim would be to keep the market rate well inside the moving exchange margins. National parity changes would thus be made by national authorities on a discretionary basis. These would be subject to overall review in an international forum, using the same general criteria that are envisaged for overview of parity adjustment in less frequent steps; but in this case the review would apply to the net change in parity effected over a substantial period, e.g. six months, or up to a maximum percentage, rather than applying to the individual parity changes, which would be at the discretion of the national authorities. In this case and in Alternative (2), technical cooperation between exchange authorities would be needed to implement the respective parity changes.

It is important to note that while each of these alternatives would involve continuous changes in parities, or in the weighted average of exchange rates in the case of managed floating, such continuous movement no longer necessarily involves any exacerbation of even shortterm fluctuations in rates of particular currencies. Countries are now inc reasingly focusing their attention on the effective exchange rate of their currency against the currencies of their trading partners together; and stability in the rate between their own currency and any other single currency, e.g. the U.S. dollar, is not to be expected even from the maintenance of a fixed effective exchange rate on their own part. What this amounts to is that in conditions in which changes in parity by various countries become a regular occurrence, a fixed effective exchange rate on the part of any single country loses operational significance, even in day-to-day operations.

Controls on capital movements may well be judged desirable by individual countries in order to provide insulation from external influences of a variety of kinds, and use of such controls should therefore be largely at the discretion of individual countries. But it would be unwise, and against the lessons of experience, to rely on capital controls as a shield for an exchange rate regime that is itself severely exposed to speculation. 
The interest of developing countries in securing an effective regime of exchange rate adjustment is essentially indirect. Together with the smaller industrial countries, the developing countries already have effective freedom of action in adjusting their own exchange rates. Their interests in this aspect of the reform lie primarily in the avoidance of both excessive fluctuations in the currencies of the main financial centers and trading countries, and of undue rigidities. As has been amply demonstrated in recent years, such rigidities impede the ability of the developed countries to maintain open import markets, and they induce restrictions on flow of capital and aid, as well as building up crises for the future. The prime interest of the developing countries in the exchange rate regime is therefore that it should operate smoothly, and be well safeguarded against breakdown.

\section{THE RESERVE REGIME}

The interest of the less developed countries in future arrangements for reserve settlements and reserve holding is direct, substantial and many sided. These countries have a special interest in the development of a reserve system on a deliberative and organized international basis. They have a special interest in regular allocations of Special Drawing Rights from a number of standpoints:

- they have traditionally had disproportionately low holdings of gold;

- they have a potentially high need for reserves;

- they feel an increasing need to avoid dependence on a single reserve centre;

- they suffer from the absence of an international reserve asset with a stable valuation base;

- and the developing countries are of course the potential beneficiaries of a link between international reserve creation and development aid, a facility which is a wholly appropriate feature of an international reserve system.

These considerations are developed further below. What also needs to be emphasized is that a fully fledged SDR system can be expected to emerge only in so far as it provides a basis for attaining effective regulation over global monetary reserves. This is the rationale of a full SDR system and its only sound foundation. Such regulation necessitates in turn the acceptance, by countries participating in the system, of commitments to limit their holdings of reserves in forms other than SDRs. For in the absence of such limitations, there can be no assurance or expectation that regulation of the supply of SDRs will regulate the level of world reserves as a whole. One may recall the experience of the SDR system in its first phase, 1970-72, when SDR allocations were overwhelmed by an explosion of foreign exchange reserves in the form of U.S. dollars and other currencies held in national centres and in Euro-currency markets. This experience 